\title{
Reconstrucción dinámica del canto lateral postexéresis de carcinoma basocelular morfeiforme
}

\author{
Lateral canthus dynamic reconstruction after basal cell carcinoma excision
}

\author{
Dra. Lianet Bermúdez-Sánchez*
}

Palabras clave: Canto lateral, párpados,

reconstrucción, colgajos, carcinoma basocelular.

Keywords: Lateral canthus, eyelids, reconstruction, flaps, basal cell carcinoma.

\begin{abstract}
RESUMEN
Los párpados constituyen zonas de alto riesgo para la presentación del carcinoma basocelular. El canto lateral resulta el menos afectado epidemiológicamente, pero implica dificultades para la reconstrucción anatómica. Existen escasas técnicas descritas exclusivamente para esta subunidad. Se presenta el caso clínico de un paciente intervenido quirúrgicamente por presentar un carcinoma basocelular morfeiforme, a quien se le realizó exéresis tridimensional de la lesión y la reconstrucción dinámica del canto lateral a partir de un colgajo en isla, tallado en la región temporal.
\end{abstract}

\section{ABSTRACT}

Eyelids are considered basal cell carcinoma high risk areas. Lateral canthus is less affected epidemiologically, but it is a difficult area for reconstruction. There are just a few techniques described for this zone. This is a case report of a patient who received surgical treatment because of a lateral canthus basal cell carcinoma. Tridimensional excision was done followed by lateral canthus reconstruction through an island flap from the temporal zone.

\section{INTRODUCCIÓN}

Tos párpados constituyen zonas de alto riesgo _ cutáneos. Se estima que de 70 a $75 \%$ de los tumores palpebrales son benignos y que sólo de 25 a 30\% son malignos. Además, se sabe que de 5 a $10 \%$ de todos los cánceres de piel se presentan en la región periocular y que el cáncer de los párpados representa más de $90 \%$ de todos los tumores malignos oculares. Aunque la mortalidad es baja, la morbilidad es significativa. ${ }^{1}$

En orden de frecuencia descendente, se plantea que la localización de los tumores palpebrales predomina en el párpado inferior (50-60\%), canto medial (25-30\%), párpado superior (15\%) y canto lateral (5\%). ${ }^{2}$

Durante el parpadeo se lubrica el ojo. En la cirugía de la región orbitaria y sus anexos, la premisa debe ser siempre la protección del ojo y el mantenimiento de la visión, de ahí la importancia funcional del párpado. ${ }^{3}$

Los defectos palpebrales creados tras la resección tumoral pueden afectar la cobertura cutánea parcial o total, con compromiso de la lamela externa, interna o ambas, cuyas repercusiones - tanto funcionales como estéticas- estarán en función de su localización y dimensiones; requieren diferentes técnicas reconstructivas, simples o complejas, utilizando colgajos o injertos cutáneos. ${ }^{4}$

\section{CASO CLÍNICO}

Acude a consulta paciente de sexo masculino de 78 años de edad, refiere la aparición de una lesión de dos años de evolución, localizada en el canto lateral izquierdo, de crecimiento lento,

Recibido:

27 octubre 2020

Aceptado:

Citar como: Bermúdez-Sánchez L. Reconstrucción dinámica del canto lateral postexéresis de carcinoma basocelular morfeiforme. Cir Plast. 2021; 31 (1): 39-42. https://dx.doi.org/10.35366/101085 
cuya mayor molestia se manifestaba a través de la triquiasis. Al examen físico se constata un fototipo II de piel, según Fitzpatrick; se aprecia lesión perlada, terebrante, de bordes mal definidos, de aproximadamente $7 \mathrm{~mm}$ en su diámetro mayor, de base sésil, asentada en el canto lateral, con extensión hacia el párpado superior y el inferior en su porción tarsal, ocasionando triquiasis (Figura 1).

Dadas las características clínicas de la lesión se decide tomar una conducta quirúrgica; para ello se realiza estudio preoperatorio que confirma el buen estado sistémico del paciente, reportándolo como apto para cirugía. Fue sometido a cirugía bajo anestesia local, se realizó exéresis tridimensional de la lesión, con un margen de $4 \mathrm{~mm}$ que dejó un defecto

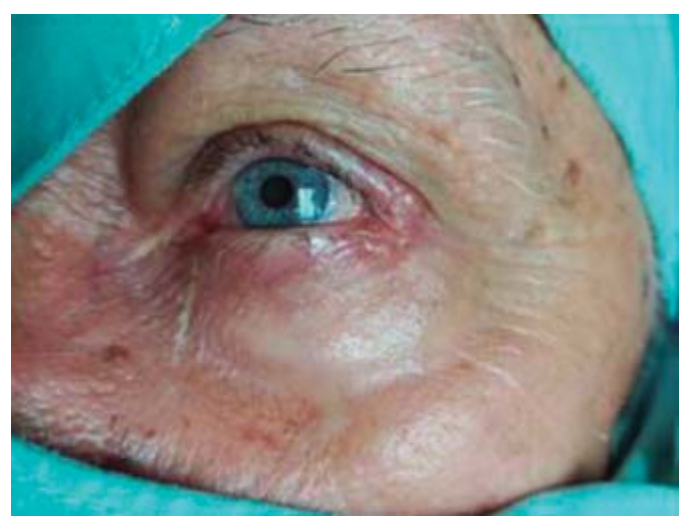

Figura 1: Lesión perlada, terebrante, de bordes mal definidos en canto lateral izquierdo.

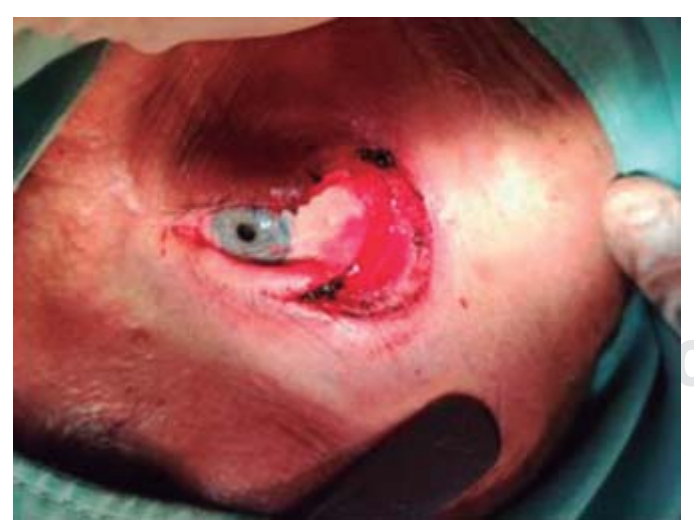

Figura 2: Imagen operatoria: defecto de la tercera parte de ambas placas tarsales y de porción pretarsal del músculo orbicular.

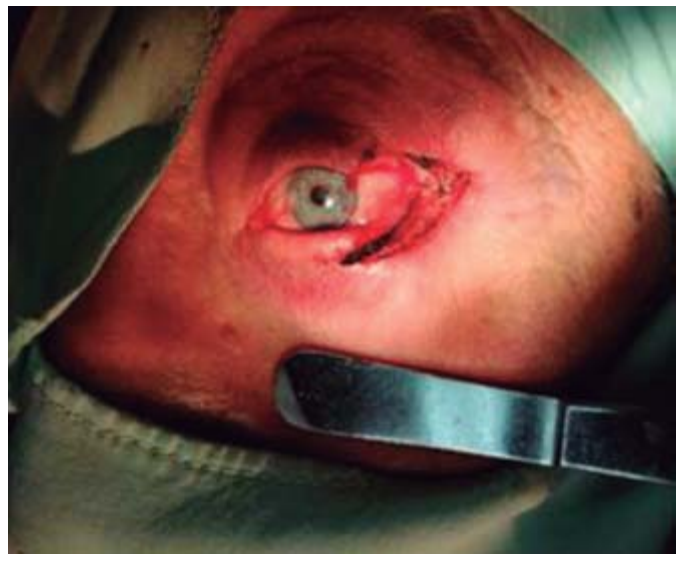

Figura 3: Reconstrucción del plano profundo de la porción preseptal del músculo orbicular para sustituir la lamela posterior.

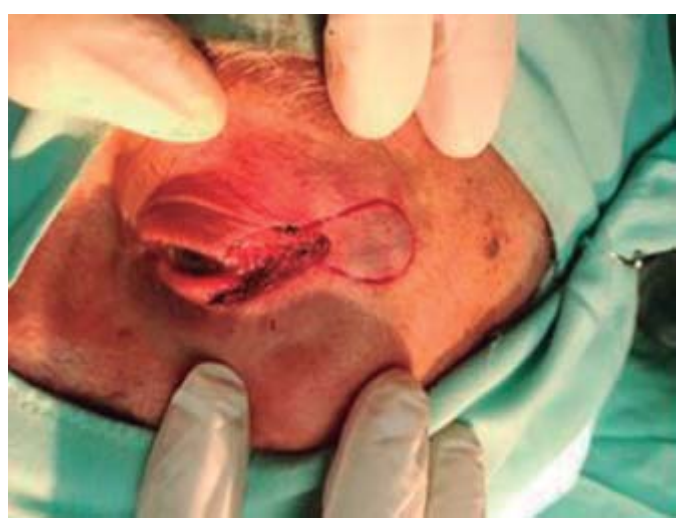

Figura 4: Colgajo en isla para cubrir completamente el canto lateral.

que implicaba la tercera parte de ambas placas tarsales y de la porción pretarsal del músculo orbicular (Figura 2). Dada la importancia de la preservación funcional de los párpados como mecanismo de protección ocular, se decidió la reconstrucción de la subunidad anatómica. En primer lugar se reconstruyó el plano profundo a expensas de la porción preseptal del músculo orbicular, lo cual devino en la sustitución de la lamela posterior (Figura 3). Acto seguido, se talló proporcional al defecto residual, un colgajo en isla, el cual en su extremo proximal se bifurcaba para asentarse sobre el área receptora del párpado superior y el inferior, cubriendo completamente el canto lateral, de manera que 


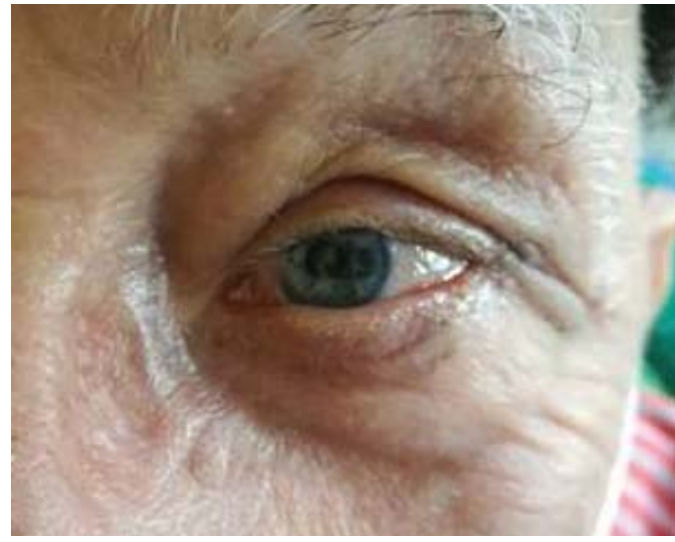

Figura 5: Resultado a tres meses de la cirugía.

reconstruyera la lamela anterior (Figura 4). Se procedió al anclaje del colgajo con sutura de Vicryl 4.0 y sutura intradérmica con Asupro 5.0.

El postoperatorio inmediato y mediato transcurrieron sin complicaciones y la sutura fue removida a los siete días. El paciente fue reexaminado en consulta a los tres meses, donde se constató un óptimo resultado estético y funcional, dado por una hendidura palpebral de $29 \mathrm{~mm}$ en su medida horizontal y de $8 \mathrm{~mm}$ en su medida vertical (Figura 5), además de la competencia de la motilidad y contractilidad palpebral. El estudio anatomopatológico reportó carcinoma basocelular morfeiforme con bordes de sección quirúrgicas libres de tumor.

\section{DISCUSIÓN}

El método reconstructivo ideal para los párpados es aquel que reproduce la estructura tarso-conjuntival y la piel como el que proporciona un párpado funcional y estéticamente aceptable, con una mínima morbilidad de la zona donante.

En la literatura consultada existe una amplia gama de colgajos para la reconstrucción del párpado superior, del inferior y del canto medial, ya que son los más afectados epidemiológicamente, pero no para el canto lateral. ${ }^{5}$

Debido a la baja incidencia de los tumores del canto lateral, se encuentran escasas referencias acerca de la reconstrucción de defectos residuales en esta zona. Los defectos pequeños del canto lateral se pueden tratar mediante aproximación directa si son menores de $2 \mathrm{~cm}$ o si se usa injerto de piel en defectos más grandes. ${ }^{6}$ Entre los colgajos a usar están los de rotación de mejilla estándar o un colgajo romboide. Si el defecto es de dimensiones significativas y compromete el canto lateral, el párpado superior y el inferior, se hacen necesarias las técnicas de reconstrucción más complejas, como el colgajo de Frické o técnicas combinadas. $^{5}$

En un estudio descriptivo realizado en el Instituto de Oncología y Radiobiología de La Habana, hallaron que, para la reconstrucción del tercio externo, se empleó mayoritariamente el colgajo rotado de mejilla, seguido del colgajo de Tenzel. ${ }^{4}$

Para la reconstrucción de un defecto quirúrgico siempre se prefiere que la zona donante tenga características similares a la zona a reconstruir. La piel de la región temporal latero-cantal muestra similitud a la piel de los párpados gracias a su estrecha relación de vecindad, que hace que la fotodinamia sea similar, por lo cual el color de la piel es muy afín, si no es que igual a la piel de los párpados. Es una zona despoblada de folículos pilosos, con una piel gruesa y adherida al plano profundo. El tejido celular subcutáneo es laxo y permite el desplazamiento de la piel sobre la aponeurosis epicraneal subyacente. ${ }^{7}$ Esto convierte a la región temporal latero-cantal en una zona de elección para la donación de tejidos en forma de colgajo.

En la reconstrucción de este defecto del canto lateral propusimos la reconstrucción con un colgajo en isla. Dicho colgajo mantiene un pedículo subcutáneo del sitio de tejido que es transferido al defecto del tejido adyacente al colgajo en isla y después es cerrado sobre el pedículo subcutáneo. ${ }^{8}$ En este caso se diseñó el colgajo con aporte vascular a través de un patrón aleatorio basado en la rama cigomáticoorbitaria de la arteria temporal superficial.

Dentro de las ventajas del colgajo en isla figura su alta plegabilidad y su escaso volumen. En este caso el colgajo en isla donado de la zona temporal latero-cantal permitió el diseño de acuerdo con las dimensiones y forma del defecto, ofreció una opción reconstructiva para la lamela anterior. El diseño bifurcado hacia el 
extremo medial favoreció la reconstrucción del defecto hacia el párpado superior y el inferior de manera simultánea, sin necesidad de recurrir a técnicas combinadas. El gran remanente tarsal propició la reconstrucción sin necesidad de interposición de cartílago entre los neoplanos lamela anterior y posterior, de manera que los extremos proximales del colgajo se fusionaron con ambas placas tarsales, sirviéndose de su estructura y dándole continuidad hasta el canto lateral.

\section{CONCLUSIONES}

La región periocular constituye un área de alto riesgo para la aparición de carcinomas basocelulares, siendo una zona de difícil reconstrucción. El canto lateral se ve implicado en la minoría de los casos. Se describió el colgajo en isla como una opción para la reconstrucción del canto lateral posterior a la remoción de un carcinoma basocelular morfeiforme, obteniéndose resultados estéticos y funcionales muy alentadores.

\section{REFERENCIAS}

1. Hernández SY, Sánchez CY, Estrada AB. Colgajos o injertos cutáneos para la corrección de defectos palpebrales de gran tamaño. Rev Cub Oftal 2018; 31 (4): 8-16.
2. Calonje JE, Brenn T, Lazar A, Billings S. McKee's pathology of the skin. 5th ed. USA: Elsevier; 2018.

3. León Abarca IR. Reconstrucción palpebral en oncología en ION SOLCA núcleo del Guayas. Ecuador: Universidad Católica Santiago de Guayaquil; 2015. Disponible en: http://repositorio.ucsg.edu.ec/ handle/3317/3134

4. González García JL, Abreu Perdomo FA, Melgares Ramos MA. Aplicación de técnicas reconstructivas en el manejo de los pacientes con tumores malignos del párpado inferior. Rev Cub Oftal 2016; 29 (2): 229-240.

5. Hernández Sánchez Y, Sánchez Carbonel Y, Estrada Amador B. Colgajos o injertos cutáneos para la corrección de defectos palpebrales de gran tamaño. Rev Cub Oftal [Internet] 2018; 31 (4). Disponible en: http://www.revoftalmologia.sld.cu/index.php/ oftalmologia/article/view/615

6. Korn BS, Kikkawa DO. Atlas video cirugía plástica y reconstructiva oculofacial. Bucaramanga, Colombia: Editorial Amolca; 2013.

7. Rouviere H, Delmas V, Delmas A. Anatomía humana descriptiva, topográfica y funcional. Tomo I. $11^{\mathrm{a}} \mathrm{ed}$. Barcelona: Elsevier Masson; 2005.

8. Aymerich Bolaños O. Generalidades de colgajos y su importancia con I reparación del daño corporal. Med Leg Costa Rica 2014; 31 (1): 49-56.

Conflicto de intereses: La autora declara no tener conflicto de intereses.

\section{Correspondencia:}

Dra. Lianet Bermúdez-Sánchez Calle Unión Núm. 253 B altos, entre Síndico y Nazareno, Reparto La Pastora, Santa Clara, Villa Clara, Cuba.

E-mail: lianetbs90@gmail.com 